\title{
Misdiagnosed Giant Renal Cyst Managed by the General Surgeon - A Case Report
}

\author{
Mbah N* \\ Department of Surgery, Chukwuemeka Odumegwu Ojukwu University, Teaching Hospital (COOUTH), Amaku, Awka. Anambra \\ State, Nigeria
}

"Corresponding author: Mbah N, Department of Surgery, Chukwuemeka Odumegwu Ojukwu University, Teaching Hospital (COOUTH), Amaku, Awka. Anambra State, Nigeria, Tel: +2348054872710;

Email: nonsodr@yahoo.co.uk

Citation: Mbah N (2018) Misdiagnosed Giant Renal Cyst Managed by the General Surgeon - A Case Report. SAJ Case Report 5: 401

Article history: Received: 30 July 2018, Accepted: 02 September 2018, Published: 03 September 2018

\begin{abstract}
Giant renal cysts are rare. Misdiagnosis is rampant in areas where the relevant ancillary investigations are neither affordable nor readily available. Therefore these lesions may inadvertently present to the general surgeon rather than to the urologist. Several options of treatment exist. Complete removal is challenging but invaluable. It offers the best opportunity for a comprehensive histological analysis of the entire lesion and eliminates the risk of recurrence in benign cases. We describe the successful open surgical excision of a symptomatic giant left renal cyst in a sixty-nine year of man who was managed by the general surgeon.
\end{abstract}

Keywords: Giant renal cyst; Misdiagnosis; Complete removal; General Surgeon

\section{Introduction}

Kidney cysts are common in the general population with an overall prevalence of $11.9 \%$ [1]. They are present in up to $50 \%$ of the population over the age of 50 years $[2,3]$. Approximately $2 / 3^{\text {rd }}$ of humans have a kidney cyst detectable by CT scan by the age of 80 years [2]. Majority of these cysts are less than $2 \mathrm{~cm}$ in size, benign, asymptomatic and treated conservatively [4]. However, giant renal cysts greater than $15 \mathrm{~cm}$ or containing more than $1500 \mathrm{mls}$ of fluid are rare [5]. The bigger the lesion, the higher the chances of associated symptoms from the mechanical pressure effect on adjacent structures as well as functional damage to the affected kidney. Curiously, some patients with massive renal cysts still remain asymptomatic for long besides the presence of an abdominal swelling [4]. The accurate diagnosis of giant renal cysts is often missed in the absence of the appropriate ancillary investigations such as excretory urography studies, contrast-enhanced computerized tomography (CECT) scan or magnetic resonance imaging (MRI) $[5,6]$. In a male patient, the differential diagnosis includes ascites, mesenteric cyst, intra-abdominal malignancy, echinococcal cyst and pancreatic pseudocyst. If accurately diagnosed preoperatively, giant renal cysts are ideally managed by the urologists using various options of treatment. When giant cysts of renal origin are misdiagnosed, they may present to the general surgeons instead.

\section{Case Report}

A 69-year old retired male farmer was referred to the general surgery unit of a private hospital based in Awka, Nigeria with an abdominal ultrasound report of a "giant complex mesenteric cyst". He gave a 1-year history of painless but progressive abdominal distention. The gentleman denied any preceding history of trauma. There was associated early satiety but no vomiting. His bowel motion was regular. There were no urinary symptoms. He was not a known hypertensive. His past medical and surgical histories were uneventful. On general examination, the patient was haemodynamicaly stable with a blood pressure of $149 / 91 \mathrm{mmHg}$ and a heart rate of 79/minute. The abdomen was globally distended, tense but non-tender. The digital rectal evaluation was unremarkable. His laboratory results showed PCV 42\%; normal serum electrolyte, urea and creatinine values. The retroviral screen was negative.

His preoperative exploratory laparotomy work-up involved grouping and cross-matching of 3-units of blood, urethral catheterization and passage of a size-18 nasogastric tube.

The intraoperative finding was a massive left sided retroperitoneal cystic mass lesion which stretched and displaced the overlying descending colon and its mesocolon (Figure 1). The mass was continuous with the inferior pole of the left kidney. The rest of 
the abdominal viscera including the liver were grossly normal. A surgical plane was developed between the overlying visceral peritoneum and the capsule of the cyst to the left hand side of the descending colon through which the most part of the cyst was bluntly freed (Figure 2). The small intra-renal part of the cyst was excised from the lower pole of the left kidney by sharp dissection using coagulating diathermy current. The cyst was removed intact, weighed $6.2 \mathrm{~kg}$ and measured $28 \mathrm{~cm}$ in its widest diameter (Figure 3 and 4). Haemostasis was secured by both suture ligation and diathermy coagulation. The inferior pole of the left kidney was repaired using the lower flap with horizontal interrupted vicryl 3/0 mattress sutures.

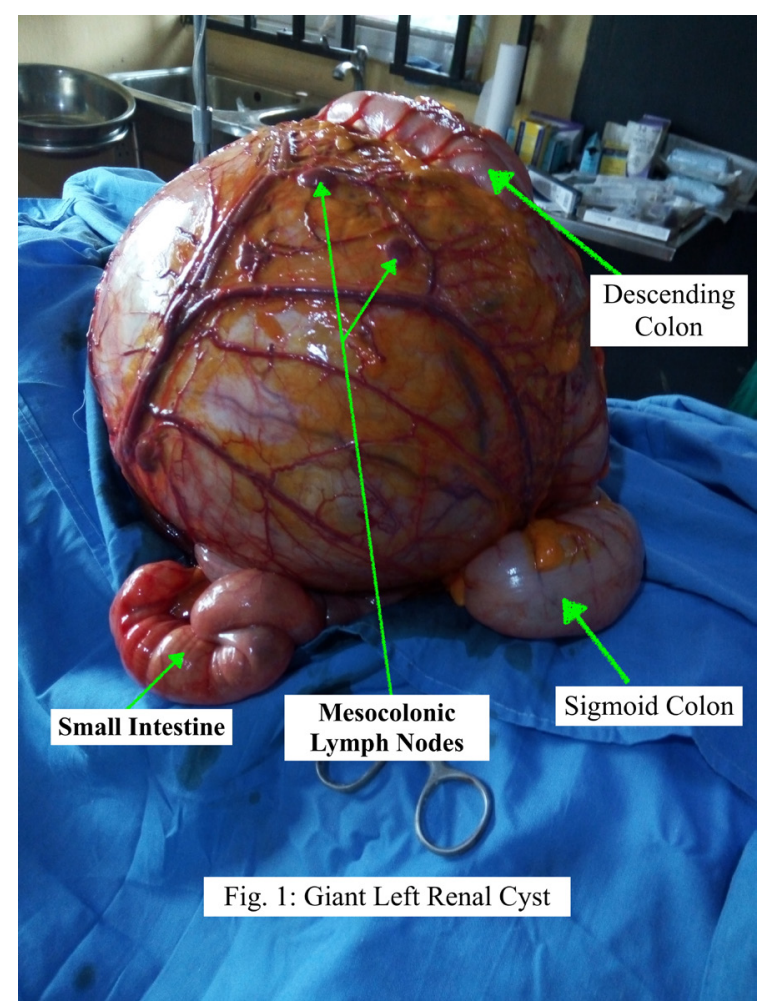

Figure 1: Giant Left Renal Cyst

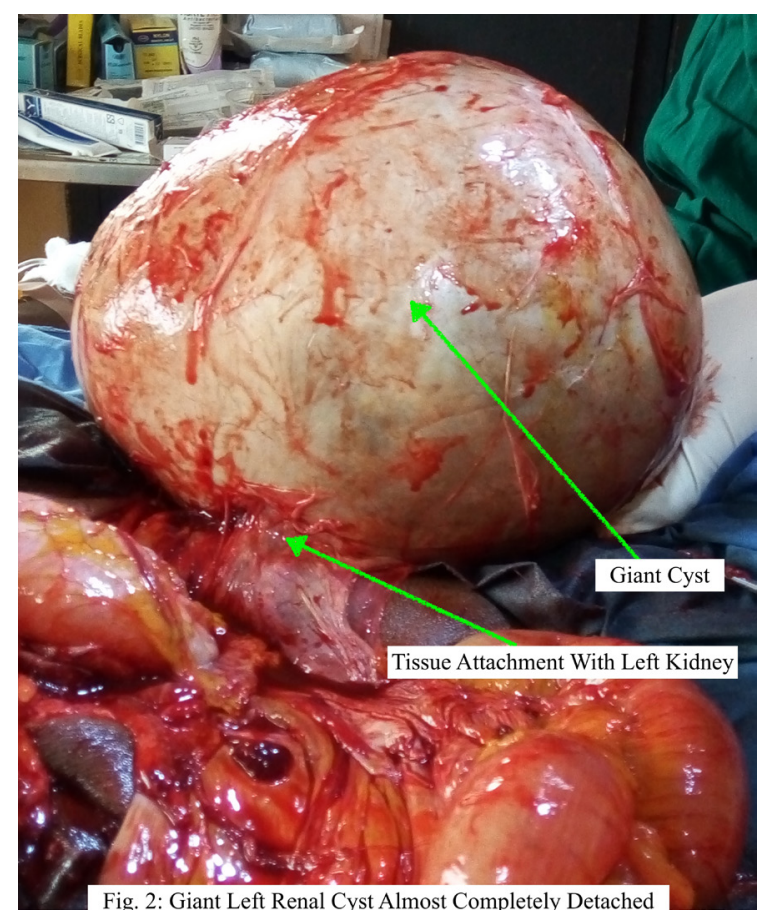

Figure 2: Giant Renal Cyst Almost Completely Detached

The laparotomy wound was closed over a large drain positioned in the left flank of the abdomen. Three units of blood were transfused postop. The patient recovered uneventfully and was discharged on the 9 th day after surgery.

The histology report of the specimen confirmed a benign renal cyst. 


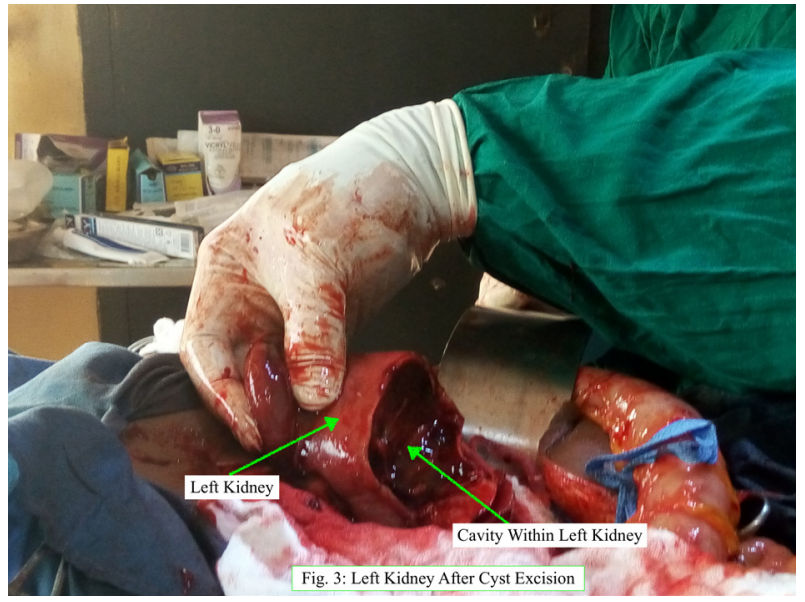

Figure 3: Left Kidney after Cyst Excision

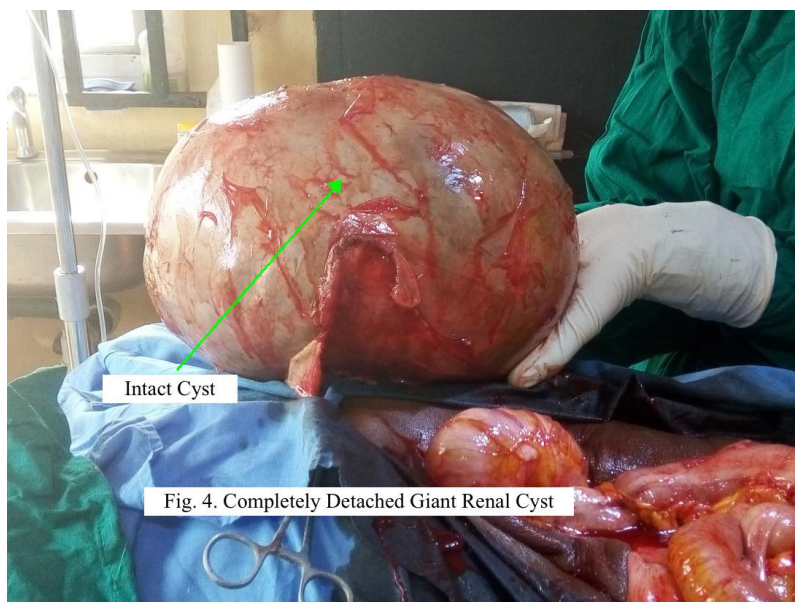

Figure 4: Detached Giant Renal Cyst

\section{Discussion}

Without ancillary investigations, misdiagnosis of giant renal cysts is common [1-5]. This is often because these lesions are not associated with any pathognomonic symptoms and signs. Riyach, et al. reported a case which was erroneously managed as ascites [4]. Urologists at the Mayo Clinic had managed a case wrongly diagnosed as obesity [5]. Our patient was referred to the general surgeon with an ultrasound report of "complex mesenteric cyst". It is known that ultrasound is limited by operator-bias and in our own case it gave misleading information. Similar limitations of ultrasound with regards to missed huge kidney cysts had been the experience elsewhere [4]. However, ultrasound scan still remains an invaluable ancillary investigation tool particularly in resource poor environments for its availability, affordability and low radiation risk. The use of excretory urography or contrast-enhanced CT scan are known to be more reliable means of achieving accurate pre-operative diagnosis of giant renal cysts [4,5]. Unfortunately, these diagnostic armamentaria are neither readily available nor affordable in our practice environment.

Enormous dimensions of kidney cyst had been reported in the medical literature [4,7]. Curiously, many cases of these giant renal cysts remained asymptomatic at presentation. Our patient presented after 1-year of onset with minimal symptoms apart from a large abdomen. Some had reported delayed presentation and/or diagnosis ranging from a few months to 20 years [3-5]. Doctors in Lagos, Nigeria managed a very large cyst on the affected right kidney which became atrophic due to late presentation but in whom there was no biochemical or clinical evidence of renal failure $[7,8]$. Therefore the presence of a functional contralateral kidney may conceal the damage from this condition and further delay the time to hospital presentation.

Renal cysts have low incidence of intrinsic malignancy as reported by several workers [3]. However, a few are associated with intracystic renal cell carcinoma. Ulker and colleagues in Turkey and Yu, et al. in China managed a case of giant kidney cyst and "simple" renal cyst respectively which contained renal cell carcinoma [3,9]. Both cases had negative preoperative features for malignancy from the cystic fluid cytology, tumour markers and fat analysis. Therefore, in centres such as ours where frozen section facilities are not available, the complete removal and comprehensive pathological evaluation of a renal cyst should be the minimum scope of treatment in order not to miss a malignant cystic kidney swelling. Giant kidney cysts are amenable to both open and laparoscopic options of treatment $[8,10]$. Less invasive procedures such as percutaneous aspiration drainage with or without injection sclerotherapy or percutaneous marsupialization which leave part of the cyst wall behind should be reserved for the very elderly or the younger patient with severe comorbidities who may be unfit for the total excision surgery. Besides, procedures other than total removal of the cyst are fraught with higher rates of fluid re-accumulation in the remnant tissue thereby requiring 
multiple interventions [8]. The cyst under this report was completely removed and the entire cyst wall demonstrated overall benign features histologically. The patient remained symptom and disease free 1-year post surgery.

When appropriately diagnosed before surgery, giant renal cysts are ideally managed under urologists as evidenced from the plethora of reports on this condition in the medical literature. Accordingly, when clinicians other than urologists successfully treat these huge lesions by default, it is useful that such expediencies in clinical practice are reported for the guidance of those who find themselves in similar position.

\section{Conclusion}

Giant renal cysts are rare but may present to the general surgeon in regions where excretory urography, contrast enhanced CT scans or MRI scanners are neither readily available nor affordable. Complete surgical removal is feasible and advisable in order to provide adequate specimen for a comprehensive histological assessment.

\section{References}

1. Rehman A, Awais M, Baloch N, Ather H (2014) Intraperitoneal marsupialization of a giant para-pelvic renal cyst: a case report. Can Urol Assoc J 8: 11-2.

2. Sharma S, Kumar V, Pannu H, Gupta D (2006) An unususal cause of giant renal mass. JIACM 7: 252-4.

3. Ulker V, Ozyurt C, Gursan A (1996) Renal cell carcinoma in a giant renal cyst. A case report and review of the literature. Int Urol Nephrol 28: 141-4.

4. Riyach O, Ahsaini M, Tazi K, Tazi MF, Mellas S, et al. (2014) A huge renal cyst mimicking ascites: a case report. BMC Res Notes 7: 39.

5. Brown JA, Segura JW, Blute ML (1998) A giant left renal cyst presenting as obesity: a unique presentation. Arch Esp Urol 51: 105-7.

6. Wood CG, Stromberg LJ, Harmath CB, Horowitz JM, Feng C, et al. (2015) CT and MR Imaging for the evaluation of cystic renal lesions and diseases. Radiographics 35: 125-41.

7. Soyemi S, Faduyile A, Oyewole O, Sanni A, Popoola A, et al. (2013) Giant right renal cyst mimicking intra-abdominal malignancy: a unique finding. World J Pathol 2: 1.

8. Bas O, Nalbant I, Sener NC, Firat H, Yesil S, et al.. (2015) Management of renal cysts. JSLS 19: e2014.00097.

9. Yu Y, Ma L, Wang Z, Zhang Z (2017) Renal cell carcinoma presenting as a simple renal cyst: A case report. Mol Clin Oncol 6: 550-2.

10. Singh I, Sharma D, Singh N (2003) Retroperitoneal de-roofing of a giant renal cyst in a solitary functioning hydronephrotic kidney with a 3-port technique. Surg Laparosc Endosc Percutan Tech 13: 404-8. 